\title{
Monográfico sobre Investigación en Interpretación Musical: Implicaciones para el Desarrollo Profesional Docente
}

\author{
Alfredo BAUTISTA ${ }^{1}$ \& Basilio FERNANDEZ-MORANTE ${ }^{2}$ \\ (1) Nanyang Technological University, National Institute of Education (Singapur) \\ ${ }^{(2)}$ Conservatorio Profesional de Música de Valencia (España)
}

(Recibido, 1 de enero, 2018; Aceptado, 15 de enero, 2018)

RESUMEN: En los últimos años, España ha observado un gran incremento en el volumen de investigaciones sobre enseñanza y aprendizaje de la interpretación musical, impulsado desde las universidades, conservatorios superiores, órganos de publicación, así como desde asociaciones académicas y profesionales. El presente monográfico es una iniciativa de la Asociación Española de Psicología de la Música y la Interpretación Musical (AEPMIM). El objetivo del monográfico es contribuir al corpus de investigación española en dicha área, con un conjunto de estudios de los que se derivan implicaciones para el desarrollo profesional de los docentes de nuestros conservatorios y escuelas de música. Tras describir el contexto de la enseñanza y la investigación musical en España, se presenta la AEPMIM y se introducen las seis investigaciones de las que consta el monográfico, centradas en: 1) la investigación-acción como recurso para la innovación educativa en conservatorios; 2) las características de diversos métodos de iniciación instrumental, concretamente de violonchelo; 3) las imágenes visuales como herramientas para el aprendizaje del canto lírico; 4) las diferencias en autoconcepto, atribuciones causales y ansiedad-rasgo asociadas a la edad y al género en estudiantes de conservatorio; 5) las ideas del profesorado de instrumento acerca de los procedimientos de evaluación; y 6) las percepciones de docentes en formación sobre el uso de herramientas tecnológicas en el aula de música. Planteamos que la mejora de la calidad de la enseñanza musical y la innovación son también responsabilidad de los investigadores, y que las políticas científicas deberían priorizar estudios de los que se deriven claras implicaciones educativas, que favorezcan la formación inicial y/o permanente del profesorado.

Palabras clave: interpretación musical, investigación, enseñanza, aprendizaje, conservatorios, escuelas de música, desarrollo profesional docente, cambio educativo, innovación.

\section{Monograph on Music Performance Research: Implications for Teacher Professional Development}

ABSTRACT: In recent years, Spain has observed a significant growth in the number of research studies related to the teaching and learning of music performance, supported by universities, higher education conservatories, publishers, as well as academic and professional associations. The current monograph is an initiative of the Spanish Association for Psychology of Music and Music Performance (AEPMIM). The goal of this monograph is to contribute to the body of research on this area, with a set of studies that pose implications for the professional development of teachers from Spanish 
conservatories and music schools. After describing the current context of music education and research in Spain, we introduce the AEPMIM and then present the six studies included in the special issue, which focus on: 1) action-research as resource for educational innovation in conservatories: 2) the features of several methods of early teaching and learning of the cello; 3) visual images as tools for the learning of lyric singing; 4) differences in self-concept, causal attributions and trait anxiety associated to age and gender in conservatory students; 5) instrumental teachers' ideas about evaluation procedures; and 6) student teachers' perceptions of the use of technological tools in the music classroom. We argue that the improvement of music teaching quality and innovation are also researchers' responsibility, and that scientific policies should prioritize research studies with clear educational implications, which foster the development of pre-service and in-service music teachers.

Keywords: music performance, research, teaching, learning, conservatories, music schools, teacher professional development, educational change, innovation.

Correspondencia: Alfredo Bautista, Research Scientist \& Lecturer. Nanyang Technological University - National Institute of Education. Center for Research in Child Development. 1 Nanyang Walk. NIE5B3-16. Singapur [637616]. Teléfono: (+65) 6219 6256. Fax: (+65) 6896 9845. E-mail: Alfredo.Bautista@nie.edu.sg.

\section{Introducción}

En los últimos diez años, España ha observado una creciente presencia de la investigación en las aulas de sus conservatorios y escuelas de música, así como en centros de enseñanza general a todos los niveles (e.g., infantil, primaria, secundaria). Este interés investigador por el aprendizaje musical, sin precedentes en nuestro país (Morales, Ortega, Conesa, \& Ruiz-Esteban, 2017), ha sido fuertemente impulsado desde las universidades y conservatorios superiores de música, así como desde órganos de publicación y asociaciones académicas y profesionales. Los resultados de las investigaciones que se llevan a cabo ven la luz con frecuencia en publicaciones tanto nacionales como internacionales, por ejemplo en revistas especializadas en educación musical (Fernández Morante \& García Orozco, 2015) y también en ciertas revistas generalistas, sobre todo mediante la publicación de monográficos (Gustems \& Calderón, 2014). En contextos de educación general, algunos ejemplos son el monográfico sobre planes de estudio y formación inicial del profesorado de música en Europa y América Latina, publicado por la Revista de Currículum y Formación del Profesorado (Aróstegui, 2010), y el reciente monográfico sobre educación musical de la Revista Española de Pedagogía (Morales, 2017). En conservatorios y escuelas de música, contamos con el monográfico publicado por Cultura y Educación (Pozo, Bautista, \& Torrado, 2008), centrado en la descripción de las concepciones y prácticas de enseñanza y aprendizaje de la interpretación musical en profesores y alumnos ${ }^{1}$ de distintas especialidades instrumentales.

El presente monográfico de Psychology, Society, \& Education es una iniciativa de la Asociación Española de Psicología de la Música y la Interpretación Musical (AEPMIM). El principal objetivo del monográfico es contribuir al corpus de investigación en interpretación musical realizada en España, con especial énfasis en la enseñanza y el aprendizaje instrumental,

\footnotetext{
${ }^{1}$ En el artículo se utiliza el género masculino de forma genérica, por simplicidad, en referencia a los géneros femenino y masculino.

(C) Psy, Soc, \& Educ, 2018, Vol. 10(1)
} 
mediante un conjunto de estudios de los que se derivan implicaciones para el desarrollo profesional del profesorado. Tras situar el monográfico en el contexto de la enseñanza y la investigación musical en España, presentamos a la AEPMIM y describimos sus principales metas y objetivos, para finalmente introducir la temática de las seis investigaciones que integran este número especial. Los editores del monográfico proponemos que la mejora de la calidad de la enseñanza musical y la innovación son también responsabilidad de los investigadores, y que las políticas científicas deberían priorizar estudios de los que se deriven claras implicaciones educativas, que favorezcan la formación inicial y/o permanente del profesorado de nuestros conservatorios y escuelas de música.

\section{Hacia nuevas metas y narrativas de investigación en educación musical}

La enseñanza de interpretación musical es un sector educativo que continúa creciendo en España (Ponce de León \& Lago, 2009). Pese a que, lamentablemente, desde las administraciones educativas se ha restado a la educación musical la importancia que merece en las enseñanzas de régimen general (Rusinek \& Aróstegui, 2015), el interés y el gusto por la interpretación musical en nuestro país siguen siendo una realidad. Según Querol Gutiérrez (2017), durante el curso 2015/16, las enseñanzas especializadas de música contaban con un total de 323.693 alumnos: $44.808,45.505$ y 8.619 alumnos en centros reglados de niveles elemental, profesional y superior, respectivamente, además de 224.761 alumnos en centros de enseñanza no reglada. Contamos con una red de 1.384 centros de enseñanza musical, la mayoría de ellos (72.8\%) públicos: 106, 194 y 23 conservatorios elementales, profesionales y superiores, respectivamente, más 965 escuelas de música (722 públicas, 243 concertadas o privadas, y 107 centros autorizados).

Ante el elevado número de centros de enseñanza musical existente hoy día, con la correspondiente inversión de fondos públicos que estos conllevan, resulta preocupante que las tasas de abandono de los estudios musicales sean tan elevadas. Por ejemplo, el grado de abandono en los conservatorios profesionales es superior al $80 \%$, y solo un $10 \%$ de los estudiantes que completan el grado profesional llega a obtener una titulación superior (Querol Gutiérrez, 2017). Son muchos los factores que contribuyen a esta realidad, incluyendo la larga duración de estos estudios, la gran inversión económica que acarrean para las familias (e.g., compra de instrumentos musicales, clases privadas), la necesidad de superar numerosas y complicadas pruebas de aptitud y de acceso, así como las dificultades intrínsecas al desarrollo de las capacidades auditivas, técnicas y artísticas que estas enseñanzas requieren (Vicente \& Aróstegui, 2003). Intervienen además factores de naturaleza personal, especialmente de tipo motivacional. Como es bien sabido, los estudios musicales a nivel profesional requieren de grandes dosis de esfuerzo y dedicación, y son pocos los que soportan las exigencias y la competitividad del sistema. La mayoría pierden el interés y abandonan por el camino (Ponce de León \& Lago, 2009). Aquí entran también en juego factores de naturaleza sociocultural, pues muchos consideran las enseñanzas artísticas como secundarias, como actividades 'para el tiempo libre'. Esta visión científica del mundo (Carbajo \& Lacárcel, 2005) contribuye a que buena parte de los estudiantes de nuestros conservatorios y escuelas de música opten por itinerarios académicos y profesionales con mejor consideración social. 
Otro factor que podría estar contribuyendo de forma decisiva al abandono de las enseñanzas musicales es el hecho de que las prácticas educativas en buena parte de los conservatorios y escuelas de música siguen ancladas en modelos y métodos tradicionales, propios de anteriores culturas del aprendizaje, especialmente en lo que respecta al aprendizaje de la interpretación (Pozo et al., 2008). La investigación etnográfica puso de manifiesto hace décadas el sistema de ideas y creencias subyacente al 'modelo conservatorio' (Burwell, 2005). Dicho modelo destaca la figura del maestro como modelo supremo, considerado artista antes que docente, y cuya reputación viene determinada por su relación con instrumentistas legendarios o por su pertenencia a determinadas escuelas (Kingsbury, 1988). Las nuevas metodologías de enseñanza constituyen una amenaza al individualismo imperante en la tradición pedagógica instrumental, dentro de un competitivo sistema en el que prima el talento. Nettl (1995) destaca también el carácter quasi religioso de las enseñanzas musicales y sus rituales, donde la música se concibe como algo inexplicable, el alumno como cliente y producto al mismo tiempo, y el profesor como ente con cualidades casi sobrenaturales, cuyos métodos ni se supervisan ni se cuestionan. El quehacer diario se deja a su completa discreción. De hecho, la investigación en esta área ha sido tan escasa durante décadas que el contexto de los conservatorios llegó a calificarse como un 'jardín secreto' (Young, Burwell, \& Pickup, 2003).

La hegemonía de los instrumentistas en los conservatorios y muchas escuelas de música en España es absoluta, priorizando la interpretación sobre otras áreas importantes como la composición y la improvisación, y por supuesto por encima de la pedagogía, la didáctica o la investigación musical (Aróstegui \& Cisneros-Cohernour, 2010). El profesorado de los conservatorios se nutre de sus propios estudiantes, en buena medida 'clones' de sus propios profesores, retroalimentación que según Pliego de Andrés (2009) es poco saludable dado que dificulta la renovación pedagógica. En su inmensa mayoría, la formación inicial de los profesores de conservatorios no ha incluido una carga de contenidos educativos y psicopedagógicos sólida. Su practicum ha sido inexistente o de muy escasa duración (en tal caso, realizado en contextos mayormente tradicionales), y sus oportunidades de participar en iniciativas de desarrollo profesional de alta calidad han sido nulas o muy limitadas (Bautista, Yau, \& Wong, 2017). Es por ello que muchos docentes instrumentistas han sido prácticamente impermeables a los nuevos enfoques educativos, pese a las innumerables críticas que ha recibido el modelo de conservatorio en los ámbitos académicos de nuestro país (e.g., Bautista, Pérez Echeverría, \& Pozo, 2010, 2011; Checa, 2004; López-Íñiguez, Pozo, \& de Dios, 2014; Torrado \& Pozo, 2008), incluso pese a las evidencias de que dicho modelo puede llegar a tener efectos negativos en los estudiantes (Burwell, 2006; Musumeci, 2005).

Se precisa, por tanto, de cambios profundos en los modelos y métodos de enseñanza musical, particularmente de lo que respecta a la interpretación (Checa, 2004; Pliego de Andrés, 2009); cambios que, como se defiende en este monográfico, deberían impulsarse no solo desde la formación inicial y permanente del profesorado y desde los propios centros, sino también desde la investigación. Consideramos que la política científica en conservatorios y escuelas de música debería establecer como uno de sus objetivos prioritarios la mejora de la calidad de la enseñanza, contribuyendo a cambiar las concepciones y prácticas del profesorado (Pozo et al., 2008). La mejora pedagógica como meta investigadora, a nuestro juicio, contrasta con otras metas comúnmente existentes entre quienes realizan investigación relacionada con el aprendizaje musical hoy día en nuestro país. Sin el propósito de establecer generalizaciones, y 
únicamente con base en nuestra propia experiencia e impresión subjetiva, sugerimos que existen ciertos perfiles investigadores bastante definidos.

Por un lado, los académicos y equipos de investigación consolidados, sobre todo dentro de las universidades, suelen marcarse metas de naturaleza puramente epistémica, priorizando el rigor teórico y metodológico de sus investigaciones sobre su relevancia práctica. Dadas las exigencias de los actuales sistemas de acreditación académica, los investigadores profesionales no suelen diseminar su trabajo en los foros a los que profesorado tiene acceso, sino que priorizan las revistas científicas y otro tipo de publicaciones especializadas, a las que generalmente sólo se tiene acceso desde hemerotecas universitarias. El impacto investigador se mide a partir del número de citas de otros investigadores y del ranking de las revistas donde uno publica. Además, el lenguaje utilizado en artículos científicos suele ser demasiado técnico e inaccesible para los docentes, y su contenido demasiado abstracto, específico y/o alejado de los problemas reales, llegando en ocasiones a carecer de sentido para el profesorado (Bautista \& Ortega-Ruíz, 2015). La meta de contribuir a mejorar calidad de la enseñanza en conservatorios y escuelas de música, o al menos algún aspecto concreto de la misma, es por tanto secundaria para muchos académicos-investigadores interesados en la música, incluso irrelevante o imposible, pues algunos no tienen formación musical y ni siquiera han estado nunca en este tipo de centros educativos.

Por otro lado, dentro de los propios conservatorios y centros de enseñanza musical superior, existen múltiples metas y narrativas investigadoras, con frecuencia bastante diferentes a las de los académicos. Por motivos curriculares, se requiere que los estudiantes de grado realicen pequeños proyectos y/o estudios de investigación con la ayuda de sus tutores (quienes, en ocasiones, tienen limitada o nula experiencia investigadora). De nuevo, el objetivo no es mejorar la calidad de la enseñanza, sino dotar al estudiante de ciertas competencias investigadoras básicas que le permitan, al menos, aprobar la asignatura en cuestión. Más allá del grado, muchos músicos y profesores de conservatorio se han embarcado en estos últimos años en estudios de postgrado, algunos no tanto por intereses investigadores intrínsecos sino más bien por abrirse futuras vías profesionales que requieren ciertos grados académicos. En efecto, el interés por realizar estudios de master y doctorado ha crecido exponencialmente entre los músicos, lo cual ha generado una proliferación de investigaciones embrionarias resultantes de trabajos fin de máster, así como un aumento significativo en las defensas de tesis doctorales relacionadas con la educación musical, la psicología de la música, la pedagogía o la didáctica musical (Morales et al., 2017). Dado que la enseñanza musical posee un espacio institucional limitado en las universidades españolas, es relativamente frecuente encontrar tesis de master o de doctorado dirigidas por investigadores que nada tienen que ver con la música, y a veces defendidas en departamentos cuya relación con la música o las artes es absolutamente tangencial. Tesis que, en ocasiones, tampoco responden a las problemáticas reales de los conservatorios y escuelas de música, realizadas sin una ambición decidida de cambiar la realidad, sino más bien por motivos extrínsecos (e.g., obtener el título de doctor para ser catedrático).

Recientes revisiones de la literatura de investigación musical España indican que los estudios que se llevan a cabo no siempre abordan tópicos de uso habitual en los conservatorios y escuelas de música. Por ejemplo, en un análisis bibliométrico de la producción científica recogida en 592 artículos publicados entre 2003 y 2013 en las revistas catalogadas en DIALNET, Gustems y Calderón (2014) encuentran que la mayoría de estudios suelen adoptar 
una óptica psicológica (25\%), seguido por temáticas de naturaleza didáctica (22\%), socioantropológica (20\%), histórica (17\%) y filosófica (16\%). Los autores subrayan que dichas temáticas investigadoras contrastan con los contenidos curriculares de los planes de estudio vigentes. Además, cuestionan la validez del contenido y el alcance de ciertas investigaciones, dado que la formación de los autores (en su mayoría provenientes de conservatorios) no se corresponde con el objeto de estudio abordado (Gustems \& Calderón, 2014). Por otro lado, la revisión de Morales et al. (2017) analiza las tendencias de la investigación española en educación musical a través de los 143 artículos publicados entre 2000 y 2015 en la base de datos Web of Science, mostrando que tanto el volumen de investigación como su grado de impacto son escasos en comparación con otras áreas afines. Los autores proponen diversas medidas para incrementar impacto de las publicaciones en el desarrollo profesional de sus autores, así como para mejorar visibilidad de la propia disciplina.

En este monográfico, defendemos que desde las administraciones educativas se deberían encontrar cauces para que la mejora pedagógica y la innovación en los conservatorios y escuelas de música se conviertan en una meta fundamental para los investigadores. Entendemos que la necesidad de potenciar la investigación entre docentes universitarios y de conservatorios, músicos y estudiantes es una necesidad real (Morales, 2017), pero que no solo por motivos de impacto y visibilidad de la disciplina, sino sobre todo por el rol que la investigación puede y debe jugar en la promoción de la calidad educativa. A nuestro juicio, asumir que la innovación y la excelencia pedagógica son también responsabilidad de los investigadores es un acto de responsabilidad social, y dicha meta no debería estar reñida con otras metas existentes entre quienes realizan investigación en educación musical hoy día. La labor de innovación pedagógica que han de realizar los conservatorios superiores mediante la puesta en marcha de proyectos de investigación es vital para la calidad de todos los niveles de enseñanza musical, puesto que dichos centros han de promover iniciativas para modernizar los objetivos curriculares y han de asegurar la coherencia del sistema educativo musical (Checa, 2004). Como plantean Ponce de León y Lago (2009), los tiempos cambian, la ciencia avanza y el arte se puede ver afectado, por lo que el músico necesita estar preparado para adaptarse a los cambios. Es preciso por tanto dotar al profesorado de conocimientos, habilidades y actitudes que permitan ofrecer a sus alumnos una formación integral, a ser exitosos como músicos y no solo como intérpretes, dado que "lo que los músicos del siglo XXI hacen y cómo lo hacen, está y continuará estando afectado por cambios sociales, económicos y tecnológicos, así como las nuevas formas de expresión creadas por los propios músicos" (Youth Music, 2002, p.1).

Por todo ello, mantenemos que es necesario hacer investigación con impacto real en las aulas, de donde se deriven claras implicaciones educativas, y ofrecer apoyos para que los investigadores puedan dar continuidad a sus estudios, diseminar los resultados entre el profesorado, y "poner su granito de arena" para mejorar las formas en que se enseña y se aprende en los conservatorios y escuelas de música. Este enfoque investigador, sin duda de orientación más pragmática o aplicada (Bautista, Wong, \& Gopinathan, 2015), podría contribuir a una formación más completa e integral del profesorado, una formación que no se limite al dominio del instrumento o conceptos teóricos, sino que tenga siempre en cuenta los hallazgos de las investigaciones más recientes (Ponce de León \& Lago, 2009). Está claro una enseñanza musical de calidad implica huir del nocivo e insano modelo de conservatorio y adoptar enfoque más constructivos (e.g., Bautista et al., 2010, 2011; Checa, 2004; López-Íñiguez et al., 2014; Torrado \& 
Pozo, 2008). Pero lo que aún no está tan claro, incluso para los propios investigadores, es cómo ayudar a los docentes a mejorar sus concepciones y cambiar sus prácticas. La literatura sugiere que dichos cambios son complejos, costosos a nivel cognitivo, emocional e incluso socio-cultural, y que no pueden lograrse por un aprendizaje directo sino más bien a través procesos de explicitación, reestructuración e integración jerárquica de las concepciones o teorías implícitas previas que mantienen los profesores (Pozo et al., 2006). En dichos procesos, la formación inicial y continua del profesorado, la investigación y el trabajo interdisciplinar toman una importancia decisiva (Fernández Morante \& Casas-Mas, 2016). Son necesarias, por tanto, más investigaciones que realicen una verdadera labor de andamiaje y que permitan a los profesores conectar teoría y práctica, como consiguen -a nuestro juicio- los estudios que se presentan en este monográfico.

\section{La Asociación Española de Psicología de la Música y la Interpretación Musical (AEPMIM)}

El presente monográfico es una iniciativa de la Asociación Española de Psicología de la Música y la Interpretación Musical (AEPMIM: https://aepmim.org/). El germen de AEPMIM surgió durante el II Congreso Nacional de Conservatorios Superiores de Música, celebrado en marzo de 2015 en el Real Conservatorio Superior de Música de Madrid, donde coincidieron varios investigadores y profesionales con un doble perfil psicológico y musical, prácticamente todos desconocidos entre sí hasta ese momento. Allí se gestó la idea de crear una asociación que aunara a especialistas tanto de la psicología como de la música, dadas las numerosas necesidades y problemas que demandan la integración de ambas disciplinas en nuestra sociedad (Fernández Morante \& García Orozco, 2015). Gracias a la gran ilusión y al esfuerzo de un grupo de personas que poco a poco fue formándose, AEPMIM fue formalmente constituida el 19 de junio de 2015.

AEPMIM es una asociación independiente, sin ánimo de lucro, de ámbito estrictamente profesional, de carácter corporativo, educativo, cultural y científico. Está integrada por licenciados y/o doctores en psicología, músicos profesionales, profesores y estudiantes interesados en la enseñanza de la música y la interpretación musical, y personas de áreas afines que comparten el interés por el avance del conocimiento científico en la confluencia entre la música y la psicología. AEPMIM sigue el camino abierto por otras asociaciones internacionales como la Society for Education, Music and Psychology Research (SEMPRE, 1972), a las que siguieron otras asociaciones de índole nacional y/o continental como la Deutsche Gesellschaft für Musikpsychologie (DGM, Alemania, 1983), Japanese Society for Music Perception and Cognition (JSMPC, Japón, 1987), European Society for the Cognitive Sciences of Music (ESCOM, Europa, 1991), Australian Music \& Psychology Society (AMPS, Australia, 1996), Korean Society for Music Perception and Cognition (KSMPC, 1998, Korea), Sociedad Argentina para las Ciencias Cognitivas de la Música (SACCOM, Argentina, 2000), Chinese Society for Music Psychology (CSMP, China, 2002), Associação Brasileira de Cognição e Artes Musicais (ABCM, Brasil, 2008) y Sociedad Colombiana para la Investigación en Educación y Psicología de la Música (PSICMUSE, Colombia, 2013).

Actualmente, AEPMIM cuenta con más de 50 miembros procedentes de diversas universidades, conservatorios y centros profesionales de España y otros países, con unas expectativas razonablemente positivas pese a las enormes dificultades que afronta la psicología de la música en nuestro país, todavía sin espacio institucional propio en el ámbito académico. 
Los miembros de AEPMIM incluyen profesionales con diversos perfiles académicos y profesionales, como por ejemplo la psicofisiología de la interpretación musical, neurociencias de la música o neuropsicología aplicada, la psicología cognitiva de la música, pedagogía musical, orientación psicoeducativa, así como formación y desarrollo profesional del profesorado de música.

Los objetivos de AEPMIM incluyen la organización de actividades de creación y difusión del conocimiento propio de esta área interdisciplinar, eventos científicos y de formación de carácter periódico (e.g., congresos, seminarios, cursos), así como el fomento de publicaciones y cooperaciones con otras asociaciones similares en el plano internacional. Los focos de interés incluyen la prevención y promoción de la salud del músico, aspectos psicológicos de la práctica educativa en la enseñanza instrumental, o la mejora de la eficacia de los procesos de aprendizaje y enseñanza, como es el caso del presente monográfico. Algunos miembros de AEPMIM están actualmente trabajando en la creación de un módulo de enseñanza superior (Master) específico en psicología de la música, como un primer paso en la búsqueda de ese espacio institucional tan necesario. A más largo plazo, se busca establecer colaboraciones permanentes entre las principales instituciones que pueden conectar formalmente la psicología con la música en España: las universidades y los conservatorios. Se pretende dar respuesta a las necesidades y demandas de los centros de formación musical que lo precisen, así como conjuntos orquestales o agrupaciones musicales.

Una de las prioridades de AEPMIM desde su fundación fue la organización del I Congreso Internacional de Psicología de la Música y la Interpretación Musical (CONYMUSICA), que tuvo lugar entre 5 y el 7 de octubre de 2017 en la Facultad de Psicología de la Universidad Nacional de Educación a Distancia (UNED) de Madrid. CONYMUSICA contó con más de 150 asistentes de más de 20 países (para más información, consultar la web del congreso: http://www.conpsimusica.es/). Los autores de los estudios que se presentan en este monográfico fueron seleccionados de entre los asistentes a dicho evento, como se explica en el siguiente apartado.

\section{Contenido y estructura del monográfico}

En agosto de 2017, Psychology, Society, \& Education invitó a 10 de los participantes en el congreso CONYMUSICA a enviar manuscritos a la revista para su revisión y eventual publicación en el presente monográfico. En nuestro e-mail inicial de invitación, se explicaba lo siguiente a los potenciales autores:

La revista Psychology, Society, \& Education (PSE) tiene prevista la publicación de un monográfico especial sobre enseñanza y aprendizaje de la interpretación musical, especialmente en el ámbito de conservatorios y escuelas de música. Nuestro objetivo es publicar un conjunto de estudios (preferentemente de naturaleza empírica) de los que se deriven claras implicaciones para la formación inicial y/o permanente del profesorado. El monográfico está abierto a todo tipo de temas de investigación, siempre y cuando se discutan de forma explícita las implicaciones para la formación docente del estudio realizado.

De los 10 autores invitados, únicamente siete enviaron trabajos a la revista, en parte debido al ajustado calendario en nuestras fechas de evaluación, edición y publicación (nótese que el plazo (c) Psy, Soc, \& Educ, 2018, Vol. 10(1) 
asignado para el de envío de manuscritos fue de dos meses, coincidiendo con el periodo vacacional de verano en España). Todas las propuestas recibidas se sometieron a evaluación externa, de acuerdo al método habitual de doble ciego. Cada trabajo fue enviado a 2-3 revisores expertos, a quienes solicitamos valorar el estudio no solo a nivel teórico y metodológico sino también su relevancia y/o interés nivel práctico, así como sus implicaciones para la formación inicial y/o permanente del profesorado de música, que debían ser discutidas de forma explícita. En concreto, en nuestra solicitud de revisión a los potenciales evaluadores externos se explicaba lo siguiente:

Es necesario que se discutan de forma explícita las implicaciones para la formación docente del estudio realizado, independientemente de la temática abordada (por ejemplo, en una sección final titulada "Implicaciones").

Seis de los siete manuscritos recibidos fueron aceptados para su publicación, todos ellos centrados en aspectos didácticos y/o psico-pedagógicos. A grandes rasgos, y de acuerdo al orden en que son presentados en el monográfico, las temáticas abordadas en estos seis estudios son: 1) la investigación-acción como recurso para la innovación educativa en conservatorios; 2) las características de diversos métodos de iniciación instrumental, concretamente de violonchelo; 3) las imágenes visuales como herramientas para el aprendizaje del canto lírico; 4) las diferencias en autoconcepto, atribuciones causales y ansiedad-rasgo asociadas a la edad y al género en estudiantes de conservatorio; 5) las ideas del profesorado de instrumento acerca de los procedimientos de evaluación; y 6) las percepciones de docentes en formación sobre el uso de herramientas tecnológicas en el aula de música. A continuación, aportamos más detalles de cada uno de estos estudios y elaboramos en su relevancia desde el punto de vista del desarrollo profesional docente.

El primer estudio lleva por título "Investigación-acción como recurso para la innovación y la mejora de la práctica educativa en conservatorios: Una experiencia en las enseñanzas elementales de música en España". Sus autores, Emilia Campayo Muñoz y Alberto Cabedo Mas, se plantean el objetivo de introducir al profesorado de música en la investigación-acción, ilustrando el empleo de dicha metodología con una exploración cualitativa de las relaciones entre competencias emocionales, estrategias de aprendizaje autorregulado, competencia percibida y su influencia en la interpretación musical. El estudio, llevado a cabo con alumnos de enseñanzas elementales de piano, permite a los autores describir los principios básicos de la investigación-acción e introducir algunos de los modelos teóricos más influyentes. También les permite formular una serie de propuestas aplicables al contexto de los conservatorios y reflexionar acerca de cómo esta metodología investigadora puede contribuir a la formación permanente de los profesores, en el sentido de ayudarles a repensar y re-describir los métodos tradicionales de enseñanza y a reforzar sus conocimientos psicopedagógicos.

El segundo trabajo, realizado por Oswaldo Lorenzo Quiles, Susana Muñoz Mendiluce y João Fortunato Soares Quadros Jr., se titula "Estudio comparativo de métodos de iniciación al violonchelo utilizados en los conservatorios de música andaluces. Implicaciones para el profesorado". Los autores parten de que existe una carencia de criterios objetivos que permitan a los profesores de instrumento justificar la selección de los métodos de enseñanza y aprendizaje que utilizan, concretamente en los niveles iniciales. Por ello, se plantean el objetivo de ilustrar un proceso sistemático que los profesores pueden potencialmente adoptar a la hora de tomar decisiones, para hacerles conscientes de las características intrínsecas de los distintos métodos existentes y de las repercusiones que estos pueden tener en el aprendizaje de los alumnos. En 
concreto, se analizan los cuatro métodos de iniciación al violonchelo más comúnmente utilizados en los conservatorios de música de Andalucía (Suzuki, Lee, Motatu, y Sassmannshaus), en función de sus aspectos didáctico-metodológicos, parámetros físicos, aspectos psicológicos y sensibilización musical. Los resultados revelan que dichos métodos de iniciación suelen dejar en manos de los docentes aspectos de alta relevancia en el desarrollo musical del alumnado, lo que pone de relieve la importancia de la formación del profesorado en metodologías de enseñanza activas, creativas y contemporáneas.

Los autores del tercer estudio, titulado "La imagen visual como herramienta docente en el aula de canto", son Ainhoa Merzero Moreno, Ana Laucirica Larrinaga y Jose A. Ordoñana Martin. Este trabajo analiza la eficacia de una intervención centrada en la enseñanza y el aprendizaje profesional del canto lírico, donde utilizan recursos didácticos basados en imágenes visuales que relacionan frases musicales con la colocación del sonido. Se compara la interpretación de un fragmento musical por parte de 30 estudiantes antes y después de la utilización de dichas imágenes en clase, por parte del docente, acompañadas de información verbal. Mediante pruebas perceptivas y entrevistas, se analiza el grado en que los estudiantes mejoran en relación a la ejecución del fragmento, al empleo del apoyo, a la construcción del legato y al reparto de la energía. Los resultados sugieren que las imágenes visuales tienen gran potencial para promover el aprendizaje de los alumnos en relación a dichas dimensiones. Por ello, los autores recomiendan introducir este tipo de recursos en la formación inicial y permanente del profesorado, con el objetivo de fomentar una mayor vinculación entre los aspectos vocal, acústico y físico en las enseñanzas de canto lírico.

Miren Zubeldia, Maravillas Díaz y Eider Goñi son los autores del cuarto trabajo, titulado "Autoconcepto, atribuciones causales y ansiedad-rasgo del alumnado de conservatorio. Diferencias asociadas a la edad y al género". El estudio parte de que es importante conocer las características de los alumnos que tienen un mejor y un peor autoconcepto musical, diferentes grados de ansiedad rasgo y atribuciones causales más o menos adaptativas, dado que dicho conocimiento permitiría a los profesores adaptar sus estrategias pedagógicas de acuerdo a las necesidades del alumnado. Los autores investigan las diferencias asociadas al género y la edad en las múltiples dimensiones del autoconcepto musical, las atribuciones causales y la ansiedadrasgo en una amplia muestra de 1126 alumnos de conservatorios profesionales y superiores, de diferentes comunidades autónomas españolas. Los resultados muestran que la adolescencia constituye un periodo especialmente crítico en relación al autoconcepto general, así como la existencia de diferencias desfavorables en las mujeres tanto en la ansiedad rasgo como en las atribuciones causales menos adaptativas. Se concluye que los profesores deberían ofrecer diferentes tipos de apoyos a estudiantes dependiendo de su edad y de su género.

La quinta investigación del monográfico lleva por título “¿Cómo evalúas a tus alumnos de instrumento? Ideas del profesorado de conservatorio acerca de los procedimientos de evaluación”. Sus autores, Aránzazu González Royo y Alfredo Bautista, plantean que pese a la abundante literatura relacionada con la fiabilidad y validez de los procedimientos de evaluación utilizados por profesores de interpretación, poco se sabe de sus ideas acerca de cómo evaluar a los estudiantes en clase y en los exámenes, o sobre el grado de acuerdo percibido con la manera de evaluar de otros profesores (e,g., compañeros de departamento). El estudio, centrado en explorar dichas cuestiones, se llevó a cabo mediante una entrevista semi-estructurada realizada a 18 profesores de varias disciplinas instrumentales. Los resultados muestran que las ideas 
mantenidas por los profesores respecto a cómo evaluar en clase difieren sustancialmente respecto a las ideas referidas a los exámenes, siendo ambas relativamente superficiales desde el punto de vista del aprendizaje del alumno, y que el grado de acuerdo entre profesores respecto a la forma de evaluar tiende a ser bajo. Con base en los resultados cualitativos obtenidos, se sugiere la necesidad de ayudar a los profesores de instrumento a explicitar y consensuar los procedimientos de evaluación por medio de iniciativas de desarrollo profesional, tanto formales (e.g., cursos, seminarios) como informales (e.g., discusiones entre compañeros).

El artículo que cierra el monográfico se titula "Percepción sobre el uso de 'Soundcool' como propuesta de intervención en la creación sonora y en el desarrollo de competencias docentes. Un estudio exploratorio en la formación inicial del profesorado". Sus autores son Adolf Murillo Ribes, María Elena Riaño Galán y Noemy Berbel Gómez. Este artículo invita a la comunidad educativa musical, desde centros de enseñanza general hasta escuelas de música y conservatorios, a reflexionar sobre las posibilidades que ofrecen las nuevas tecnologías en el aula. Se presenta un estudio exploratorio sobre las percepciones de futuros maestros de música acerca del uso del sistema 'Soundcool', una herramienta tecnológica diseñada para la creación sonora colaborativa mediante dispositivos móviles. Tras una intervención realizada en el ámbito de la formación inicial de profesorado, se administró un cuestionario a dos grupos de estudiantes (con y sin formación musical previa). Los resultados muestran que, independientemente del grado de formación musical, los participantes valoraron 'Soundcool' muy positivamente, considerando que las nuevas tecnologías contribuyen al desarrollo de competencias docentes relacionadas con la creatividad, el trabajo colaborativo y la innovación, todas ellas competencias fundamentales en el desempeño profesional del futuro maestro de música.

Los editores del monográfico consideramos que estas seis investigaciones conectan en buena medida con la realidad de los conservatorios y escuelas de música, lo que permitirá a los lectores establecer interesantes conexiones entre teoría y práctica. Como se discutió anteriormente, somos conscientes de que no es posible cambiar las concepciones y métodos de enseñanza del profesorado de forma directa, por mera exposición a nuevas ideas o planteamientos (Pozo et al., 2006), incluso aun siendo relevantes para el profesorado. Mejorar la calidad de la educación musical requerirá de una compleja y costosa labor de andamiaje, de trabajo colaborativo entre los centros educativos (profesores, equipos directivos), los formadores del profesorado (docentes universitarios, equipos de formación continua) y también, como hemos argumentado en este artículo, los propios investigadores (académicos universitarios, conservatorios superiores, estudiantes de grado y postgrado). Trabajos como los presentados en este número especial (e.g., intervenciones, análisis de materiales didácticos, estudios de caso, análisis de las creencias o concepciones del profesorado) pueden ser importantes catalizadores que estimulen y promuevan cambios, aunque sean modestos, contribuyendo a que los discursos científicos tengan alguna influencia real en las aulas.

Sin duda, mejorar la calidad de la educación en nuestros conservatorios y escuelas de música también requerirá la participación activa de asociaciones académico-profesionales (como la AEPMIM), de los órganos de publicación y difusión del conocimiento (e.g., revistas científicas y de divulgación), y especialmente de las administraciones educativas (e.g., legisladores educativos, agencias de financiación de proyectos científicos), quienes han de ofrecer apoyos para que los investigadores puedan dar continuidad a sus proyectos e intentar traducir sus resultados en contextos prácticos. Esperamos que este monográfico contribuya a crear dichos 
canales de colaboración interdisciplinar y, en último término, a mejorar la forma en que se enseña y se aprende en nuestros conservatorios y escuelas de música.

\section{Referencias}

Aróstegui, J. L. (2010). Formación del profesorado de música: planes de estudio en Europa y América Latina. Profesorado. Revista de Currículum y Formación de Profesorado, 14(2), 3-7.

Aróstegui, J. L., \& Cisneros-Cohernour, E. (2010). Reflexiones en torno a la formación del profesorado de música a partir del análisis documental de los planes de estudio en Europa y América Latina. Profesorado. Revista de Currículum y Formación de Profesorado, 14(2), 180-189.

Bautista, A., \& Ortega-Ruíz, R. (2015). Teacher professional development: International perspectives and approaches. Psychology, Society and Education, 7(3), 240-251.

Bautista, A., Pérez Echeverría, M. P., \& Pozo, J. I. (2010). Music performance teachers' conceptions about learning and instruction: A descriptive study of Spanish piano teachers. Psychology of Music, 38(1), 85-106.

Bautista, A., Pérez Echeverría, M. P., \& Pozo, J. I. (2011). Concepciones de profesores de piano sobre la evaluación. Revista de Educación, 355, 443-466. doi: 10-4438/1988592X-RE-2011-355-032.

Bautista, A., Wong, J., \& Gopinathan, S. (2015). Teacher professional development in Singapore: Depicting the landscape. Psychology, Society and Education, 7(3), 311-326.

Bautista, A., Yau, X., \& Wong, J. (2017). High-quality music teacher professional development: A review of the literature. Music Education Research, 19(4), 455-469. doi: 10.1080/14613808.2016.1249357

Burwell, K. (2005). A degree of independence: Teachers approaches to instrumental tuition in a university college. British Journal of Music Education, 22(3), 199-215.

Burwell, K. (2006). On musicians and singers. An investigation of different approaches taken by vocal and instrumental teachers in higher education. Music Education Research, 8(3), 331-347.

Carbajo, C., \& Lacárcel, J. (2005). La valoración social de la educación musical escolar y del docente de música de Primaria en el umbral del siglo XXI. Publicaciones, 35, 11-38.

Checa, R. (2004). Cambio de modelo en la formación del profesorado de las enseñanzas de Música. Revista Electrónica de LEEME (Lista Electrónica Europea de Musica en la Educación), 14, 1-11.

Fernández Morante, B., \& Casas-Mas, A. (2016). Re-lecturas sobre Wundt y Seashore y nacimiento de AEPMIM. La psicología en la música y con los músicos. Epistemus, 4(1), 133-160.

Fernández Morante, B. \& García Orozco, J. (2015). De la psicología de la música a la cognición musical: Historia de una disciplina ausente en los conservatorios. Artseduca, 10, 38-60.

Gustems, J., \& Calderón, D. (2014). Estudio bibliométrico de los artículos de educación musical incluidos en DIALNET 2003-2013. LEEME, Lista Europea Electrónica de Música en la Educación, 33, 27-39. 
Kingsbury, H. (1988). Music, talent and performance: A conservatory cultural system. Filadelfia: Temple University Press.

López-Íñiguez, G., Pozo, J. I., \& de Dios, M. J. (2014). The older, the wiser? Profiles of string instrument teachers with different experience according to their conceptions of teaching, learning, and evaluation. Psychology of Music, 42(2), 157-176.

Morales, A. (2017). Presentación. La educación musical, una mirada del pasado al futuro. Revista española de pedagogía, 75(268), 389-398.

Morales, A., Ortega, E., Conesa, E., \& Ruiz-Esteban, C. (2017). Análisis bibliométrico de la producción científica en Educación Musical en España. Revista española de pedagogía, 75(268), 399-414.

Musumeci, O. (2005). Hacia una educación auditiva humanamente compatible. ¿Sufriste mucho con mi dictado? Actas de las Primeras Jornadas de Educación Auditiva, UNLP, La Plata.

Nettl, B. (1995). Heartland excursions: Ethnomusicological reflections on schools of music (Vol. 415). Urbana: University of Illinois Press.

Pliego de Andrés, V. (2009). La formación de los músicos y de los profesores de música. Boletín de la Institución Libre de Enseñanza, 7475(Octubre), 69-90.

Ponce de León, L., \& Lago, P. (2009). Necesidades de orientación en los conservatorios profesionales de música. Revista Electrónica de LEEME (Lista Electrónica Europea de Musica en la Educación), 24, 63-76.

Pozo, J. I., Bautista, A., \& Torrado, J. A. (2008). El aprendizaje y la enseñanza de la interpretación musical: cambiando las concepciones y las prácticas. Cultura y Educación, 20(1), 5-15.

Pozo, J. I., Scheuer, N., Pérez Echeverría, M. P., Mateos, M., Martín, E., \& de la Cruz, M. (Eds.). (2006). Nuevas formas de pensar la enseñanza y el aprendizaje: las concepciones de profesores y alumnos. Barcelona: Graó.

Querol Gutiérrez, M. C. (2017). Análisis del modelo de liderazgo en la dirección de los conservatorios profesionales en España "Tesis doctoral inédita": Universidad de Granada.

Rusinek, G., \& Aróstegui, J. L. (2015). Educational policy reforms and the politics of music teacher education. In C. Benedict, P. Schmidt, G. Spruce, \& P. Woodford (Eds.), The Oxford Handbook of Social Justice in Music Education (pp. 78-90). Oxford: Oxford University Press.

Torrado, J. A., \& Pozo, J. I. (2008). Metas y estrategias para una práctica constructiva en la enseñanza instrumental. Cultura y Educación, 20(1), 35-48.

Vicente, A., \& Aróstegui, J. L. (2003). Formación musical y capacitación laboral en el Grado Superior de Música, o el dilema entre lo artístico y lo profesional en los conservatorios. Revista Electrónica de LEEME (Lista Electrónica Europea de Musica en la Educación), 12, 1-14.

Young, V., Burwell, K., \& Pickup, D. (2003). Areas of study and teaching strategies instrumental teaching: A case study research project. Music Education Research, 5(2), 139-155.

Youth Music. (2002). Creating a land with music: the Work, Education and Training of Professional Musicians in the 21st Century. London: Youth Music. 